\title{
Validade de conteúdo de questionários de coordenação motora para pais e professores*
}

\section{Content validity of motor coordination questionnaires for parents and teachers}

\author{
Tatiana Teixeira Barral de Lacerda ${ }^{1}$, Lívia de Castro Magalhães², \\ Márcia Bastos Rezende ${ }^{3}$
}

\begin{abstract}
LACERDA, T. T. B.; MAGALHÃES, L. C.; REZENDE, M. B. Validade de conteúdo de questionários de coordenação motora para pais e professores. Rev. Ter. Ocup. Univ. São Paulo, v. 18, n. 2, p. 63-77, maio/ago., 2007.
\end{abstract}

\begin{abstract}
RESUMO: INTRODUÇÃO: O termo Transtorno do desenvolvimento da coordenação (TDC) tem sido usado para referir às crianças que, na ausência de lesões do sistema neuromotor, apresentam dificuldades para realizar tarefas de vida diária que requerem coordenação motora. Face à escassez de testes de coordenação motora, validados para a criança brasileira, iniciou-se o processo de criação e validação da Avaliação da Coordenação e Destreza Motora - ACOORDEM. O teste é dividido em 3 partes, sendo duas compostas por itens de observação direta do desempenho motor da criança e uma terceira parte que consiste de dois questionários estruturados, que visam avaliar o desempenho funcional da criança em casa e na escola. OBJETIVO: O objetivo geral deste estudo foi examinar a validade de conteúdo dos Questionários de Pais e Professores da ACOORDEM. MÉTODO: um painel de experts, composto por nove profissionais, 11 pais e sete professores, avaliou a qualidade dos itens dos Questionários. O Questionário para Professores é composto por 73 itens e o de Pais por 108. RESULTADOS: Os resultados da avaliação deram suporte à validade de conteúdo dos Questionários de Pais e Professores, uma vez que mais de $87 \%$ dos itens foram considerados de boa qualidade. CONCLUSÃO: Como resultado do painel de experts foi feita revisão e modificações nos questionários, que contribuíram para redução no número de itens e para confirmar a adequação do instrumento às necessidades dos pais e profissionais que lidam com crianças com problemas de coordenação motora.
\end{abstract}

DESCRITORES: Desenvolvimento infantil. Destreza motora. Validade dos testes. Transtornos das habilidades motoras.

\footnotetext{
* Este trabalho é parte integrante da dissertação denominada "Estudo sobre a validade dos Questionários de Pais e Professores da ACOORDEM - Avaliação da Coordenação e Destreza Motora”, apresentada ao Programa de Mestrado em Ciências da Reabilitação da Universidade Federal de Minas Gerais em 30 de março de 2006.

1 Fisioterapeuta, Mestre em Ciências da Reabilitação, Professora Assistente, Pontifícia Universidade Católica de Minas Gerais - PUCMG.

2 Terapeuta Ocupacional, Doutora em Educação, Professora Associada do Depto. de Terapia Ocupacional, Universidade Federal de Minas Gerais - UFMG.

3 Terapeuta Ocupacional, Doutora em Ciências Biológicas, Professora Adjunta do Depto de Terapia Ocupacional, UFMG.

Endereço para correspondência: Tatiana Teixeira Barral de Lacerda - Avenida Aníbal de Macedo, 904. Bairro Arcádia, Contagem, MG. Cep: 32041-370.e-mail: tatianabarral@terra.com.br
} 


\section{INTRODUÇÃO}

$\mathrm{C}$ rianças que apresentam problemas de coordenação motora, que têm dificuldade para aprender tarefas motoras novas e realizar atividades de vida diária em casa, na escola e em ambientes infantis, têm sido examinadas sob diferentes perspectivas. A literatura nessa área é confusa, pois na ausência de terminologia unificada, essas crianças, até recentemente, recebiam diagnósticos variados, tais como disfunção cerebral mínima, dispraxia do desenvolvimento, síndrome da criança desajeitada, disfunção sensório-motora do desenvolvimento, entre outras (CERMAK et al., 2002). Entretanto, em 1996, em um encontro de pesquisadores realizado no Canadá, decidiu-se adotar o termo Transtorno do Desenvolvimento da Coordenação (TDC), usado pelo DSM-IV, para se referir às crianças que, na ausência de lesões do sistema neuromotor, apresentam dificuldades para realizar tarefas de vida diária que envolvem coordenação motora. O desenvolvimento motor de crianças com TDC geralmente é mais lento do que o de crianças normais e o pobre desempenho em atividades motoras típicas da infância interfere na participação social e no relacionamento com os colegas, podendo levar a criança a experimentar o isolamento e a marginalização (GEUZE, 2003; MANDICH; POLATAJKO, 2003).

Muitas crianças com esse distúrbio, que se caracteriza principalmente por falhas na coordenação motora, são encaminhadas para clínicas de fisioterapia e terapia ocupacional e seu diagnóstico nem sempre é imediato. Além da questão da nomenclatura confusa, os critérios para diagnóstico são inconsistentes e não há testes clínicos específicos para identificar essa condição (GEUZE et al., 2001; DUNFORD et al., 2004). Segundo Dunford et al. (2004), menos da metade das crianças encaminhadas para tratamento devido a sinais de TDC, se enquadra nos critérios para diagnóstico. Como o diagnóstico é difícil, muitas vezes o profissional, fisioterapeuta ou terapeuta ocupacional, se perde no direcionamento da intervenção apropriada. Segundo extensa revisão feita por Geuze et al. (2001), vários testes motores têm sido utilizados para diagnóstico do TDC, mesmo não tendo sido criados especificamente para tal fim, sendo que os mais citados na literatura são: o Movimento $\mathrm{ABC}$ - MABC (HENDERSON; SUDGEN, 1992), o teste de Gubbay (GUBBAY, 1975), e o Bruininks Ozeretsky Teste de Proficiência Motora BOTMP (BRUININKS, 1978), além de avaliações clínicas e neurológicas (MUTTI et al., 1978).

Embora a literatura internacional faça referência a esses instrumentos para detecção de problemas de coordenação, tais testes têm aplicação restrita em nosso país, uma vez que não existem normas para crianças brasileiras. Face à escassez de testes de desenvolvimento motor, validados para a criança brasileira, Magalhães e Rezende (MAGALHÃES et al., 2004) iniciaram o processo de criação da Avaliação da Coordenação e Destreza Motora - ACOORDEM, teste específico para a detecção do TDC em crianças brasileiras de quatro a oito anos de idade.

A criação da ACOORDEM foi norteada pela Classificação Internacional de Funcionalidade (CIF), proposta pela OMS (OMS, 2003) para considerar o impacto das doenças em três áreas: estrutura e função do corpo, atividade funcional e participação social. De acordo com essa classificação, é essencial documentar o impacto do estado de saúde na funcionalidade do indivíduo, mudando, assim, do foco centrado na doença para as conseqüências da doença, levando em consideração a interação entre fatores pessoais e contextuais (BATTAGLIA et al., 2004). A ACOORDEM tem como proposta avaliar a criança sob diferentes perspectivas, estando previstas oportunidades para examinar desempenho nas três áreas de função definidas pela CIF: (a) avaliação das habilidades sensório-motoras, por meio da observação de itens puramente motores como força, equilíbrio e coordenação motora (Estrutura e função do corpo), (b) observação informal do desempenho da criança em tarefas escolares que exigem coordenação como recorte, escrita e traçado (Atividade) e (c) avaliação do desempenho funcional em casa e na escola, além das preferências no brincar e comportamento com colegas e familiares, por meio dos questionários de pais e professores (Atividade \& Participação). Com a observação da criança sob diferentes condições, espera-se obter uma melhor compreensão da relação entre as habilidades motoras e os fatores que contribuem positivamente ou que restringem a participação da criança em casa e na escola.

Enfocando principalmente as atividades funcionais e aspectos da participação social da criança, os questionários de pais e professores, examinados no presente estudo, foram elaborados a partir do modelo conceitual para a prática de terapeutas ocupacionais e fisioterapeutas em escolas públicas, proposto por Anita Bundy e Carter (1991). Além do trabalho de Bundy e Carter (1991), os questionários da ACOODEM foram também baseados no exame dos itens do Developmental Coordination Disorder Questionnaire - DCDQ (WILSON et al., 2000) do MABC-Checklist (HENDERSON; SUDGEN, 1992), em revisão da literatura sobre as brincadeiras típicas de crianças de quatro a oito anos de idade e na experiência clínica das autoras (MAGALHÃES et al., 2004). Sendo 
assim, os questionários para pais e professores da ACOORDEM foram desenvolvidos buscando criar recursos objetivos para a coleta de informações sobre a atividade funcional e participação social da criança, nos seus contextos usuais de desempenho, em casa e na escola. Os questionários são compostos por itens simples a serem respondidos pelos pais e professores, que pontuam o comportamento e o desempenho motor da criança, de acordo com a frequiência do comportamento observado. $\mathrm{Na}$ versão original os questionários são longos, uma vez que o de professores tem 73 itens e o de pais 108 itens, mas espera-se que no processo de validação sejam reduzidos a um formato de mais fácil manejo. Naturalmente os questionários podem vir a ser úteis como instrumento de triagem para TDC, mas espera-se que sua maior contribuição seja no mapeamento das dificuldades motoras da criança, em casa e na escola, o que é essencial para o planejamento da intervenção.

Embora fisioterapeutas e terapeutas ocupacionais brasileiros tenham pouco envolvimento com o processo de criação e validação de testes, é importante ressaltar que o diagnóstico correto é a base da intervenção adequada. Assim, o objetivo deste estudo é dar continuidade ao processo de validação da ACOORDEM, examinando a validade de conteúdo dos questionários de pais e professores. Este trabalho foi realizado entre maio e setembro de 2005, no contexto do Programa de Mestrado em Ciências da Reabilitação da Universidade Federal de Minas Gerais, sendo parte da Dissertação denominada "Estudo sobre a validade dos Questionários de Pais e Professores da ACOORDEM". A pesquisa foi aprovada pelo Comitê de Ética em Pesquisa da UFMG (COEP), parecer numero ETIC 521/04.

Validade de conteúdo é definida por Anastasi e Urbina (2000) como o exame sistemático do conteúdo do teste para determinar se ele abrange uma amostra representativa do domínio de comportamento e ser medido. A determinação da validade de conteúdo é um passo essencial no desenvolvimento de novos instrumentos e deve ser feita precocemente, para examinar se os conceitos abstratos, que originaram o teste, estão representados adequadamente, como expresso por indicadores observáveis e mensuráveis da qualidade dos itens. Embora haja numerosos métodos empíricos para estabelecer validade de conteúdo, o método que parece ser mais efetivo é pedir a um painel de experts (juízes) para comparar os objetivos do teste com seu conteúdo (HALEY et al., 2001; EXNER, 1993). O resultado do painel de experts é usado para definir os itens que serão mantidos, revisados ou eliminados.

\section{CASUÍSTICAEMETODOS}

\section{Participantes}

Os participantes deste estudo foram os componentes do painel de análise dos itens. Não existem regras específicas para determinar o número adequado de juízes para participar da avaliação do conteúdo de testes, mas foi feita tentativa de obter o maior número possível de participantes. Como os questionários da ACOORDEM são voltados para pais e professores, os participantes foram divididos em três grupos distintos:

(a) Profissionais que trabalham com crianças com TDC, tanto na clínica quanto em pesquisas. Este grupo incluiu terapeutas ocupacionais e pesquisadores de várias regiões do país. Os terapeutas ocupacionais deveriam ter reconhecida experiência, de no mínimo 3 anos, na avaliação e tratamento de crianças com problemas de coordenação motora. Os terapeutas que trabalham nessa área ainda são poucos e só foram incluídos no painel aqueles com treinamento no tratamento de crianças com TDC, que participaram de cursos na área, no Brasil e/ou no exterior, e que relatam atender a essa clientela. Os pesquisadores incluídos foram convidados a participar do painel devido a trabalhos que vêm desenvolvendo com crianças com TDC. Esse grupo de juizes foi denominado grupo de profissionais.

(b) Pais de crianças que apresentam sinais de TDC, selecionados em consultórios particulares e clínicas de atendimento infantil, por meio da indicação dos terapeutas que participaram do grupo de profissionais. Os pais deveriam apresentar segundo grau completo, boa habilidade de leitura e foram selecionados devido à sua capacidade para perceber as dificuldades motoras dos filhos e para ler e responder aos questionários de avaliação dos itens. Foi dada preferência a pais de crianças que freqüentam serviços privados, por se considerar que esses pais, de maior poder aquisitivo, têm maior acesso à educação formal e, portanto, maior habilidade não apenas para ler o questionário mas, principalmente, para avaliar qualitativamente os itens.

(c) Professores do ensino infantil e fundamental de escolas públicas e privadas, localizadas na Grande-BH. Foram recrutadas professoras com experiência didática de no mínimo de cinco anos, com experiência em lidar com crianças que apresentam dificuldade escolar conseqüente a problemas de coordenação motora. 


\section{Instrumentação}

O Questionário de Professores é composto por 73 itens divididos em quatro partes. A primeira parte avalia a habilidade da criança para expressar o que está aprendendo e é composto por 19 itens. A segunda e a terceira parte medem, respectivamente, a habilidade para assumir o papel de estudante e a mobilidade e participação em jogos e brincadeiras, contendo cada uma delas 21 itens. A última parte, com 12 itens, informa sobre desempenho em atividades de vida diária. O Questionário de Pais avalia o comportamento da criança em casa e o desempenho durante as brincadeiras do dia-a-dia. Ele é dividido em quatro partes e composto, ao todo, por 108 itens. A primeira parte avalia a mobilidade e habilidade para participar de jogos motores, contendo um total de 35 itens. Esta parte inclui, ainda, um quadro descritivo das principais brincadeiras (28 itens) que fazem parte do repertório de crianças brasileiras, no qual se deve assinalar a freqüência observada e com quem a criança brinca. O desempenho nas atividades de vida diária é avaliado na segunda parte do questionário (19 itens); e na terceira estão incluídas as habilidades relacionadas ao papel de estudante (15 itens). Por fim, a última parte engloba os comportamentos, hábitos e rotinas da criança em casa e é composto por 11 itens.

\section{Procedimento}

Terapeutas ocupacionais e pesquisadores, devido à sua experiência na avaliação de crianças, dentro dos contextos familiar e escolar, foram orientados a examinar os dois questionários. Os pais e professores avaliaram apenas seus questionários específicos. Cada questionário foi acompanhado de termo de interesse, explicando os objetivos do estudo e solicitando a colaboração na avaliação dos itens. Foram distribuídos um total de 71 questionários; 11 para profissionais, 25 para pais e 35 para professores.

A qualidade dos itens dos questionários foi avaliada em seis critérios: 1) o item está bem redigido e é de fácil compreensão?; 2) o item é fácil de ser observado nas rotinas diárias em casa/na escola?; 3) o item representa aspecto relevante para o desempenho em casa/na escola?; 4) o item contribui para dar uma boa visão do desempenho motor em casa/na escola?; 5) o item contribui para dar uma boa visão do comportamento em casa/na escola? 6) o item tem potencial para diferenciar crianças com e sem dificuldade motora? Os participantes foram orientados a pontuar cada critério conforme sua opinião sobre cada item, da seguinte maneira: escore 1 - Concordo totalmente, escore 2 - Concordo parcialmente, escore 3 - Discordo parcialmente e escore 4 - Discordo totalmente. No caso específico do Questionário de Professores, deveria ser indicada, ainda, a faixa etária mais apropriada para inclusão do item (4 a 5, 6 a 7, 8 anos ou todas as idades). Havia espaço adicional para comentários, no qual os participantes poderiam dar sugestões ou fazer críticas sobre a adequação dos itens. Ao término dos questionários, os participantes deveriam, ainda, responder a duas perguntas: Qual a sua opinião final sobre os questionários? e Você acredita que pais/professores terão facilidade e interesse em respondêlo?.

\section{Análise dos dados}

Uma vez que o índice de concordância é a medida mais utilizada para determinar a validade de conteúdo, o índice de, no mínimo, $80 \%$ de concordância entre os avaliadores quanto à boa qualidade dos itens, usado em vários trabalhos (HALEY et al., 1991; HARRIS; DANIELS, 1996), foi estabelecido para este estudo. Nem todos os itens deveriam ser avaliados por todos os 6 critérios, uma vez que nem todas as perguntas eram pertinentes a todos os itens. Desta forma, foi realizada uma média dos critérios relevantes, sendo estabelecido que o item deveria obter a média de $80 \%$ de escores 1 e 2 (Concordo totalmente e Concordo parcialmente) para ser considerado adequado para ser mantido nos questionários. Os resultados da análise da qualidade dos itens constituiriam a base para modificar os questionários, com a supressão ou revisão de itens, para garantir maior adequação dos itens ao seu objetivo original.

\section{RESULTADOS}

Foram distribuídos 71 questionários; sendo 11 para profissionais, 25 para pais e 35 para professores, sendo 25 para professores de escolas privadas e 10 para professores de escolas públicas. Dos questionários entregues para profissionais, oito foram para terapeutas ocupacionais e três para pesquisadores. Destes, apenas um terapeuta ocupacional e um pesquisador não devolveram os questionários respondidos. Assim, dos questionários enviados para profissionais, apenas nove $(81,8 \%)$, sendo sete de terapeutas ocupacionais e dois de pesquisadores, foram respondidos e entregues no prazo determinado.

Os terapeutas ocupacionais indicaram um total de 25 pais e 25 professores de escolas privadas para colaborarem 
na avaliação dos questionários. Dos questionários de pais, 11 foram devolvidos na data determinada. Outros 5 foram devolvidos posteriormente e não puderam entrar no estudo, pois a análise dos dados já havia sido concluída. Além dos 25 questionários entregues para os professores de escolas privadas, mais 10 questionários foram entregues, pessoalmente pela primeira autora do trabalho, para professores de três escolas públicas. No entanto, apenas sete questionários de professores, todos de escolas privadas, foram devolvidos. Apesar de exaustivas tentativas, nenhum dos professores da rede pública devolveu os questionários respondidos.

Assim, foram totalizados 20 questionários de pais (11 pais e nove profissionais) e 16 questionários de professores (sete professores e nove profissionais) respondidos. De uma forma geral, todos os participantes do painel avaliaram bem os questionários, pois nenhum dos participantes considerou os questionários como "Fraco" ou "Regular". Mais de 75\% indicaram acreditar que pais e professores teriam facilidade e interesse em respondê-los.

Conforme avaliação feita pelos profissionais e pais, o Questionário de Pais apresentou oito itens (7,4\%), dos 108 avaliados, classificados como abaixo do critério de $80 \%$ de escores indicadores de boa qualidade dos itens (Tabela 1). Três itens (Maneja controle de vídeo-game com destreza; É cuidadoso com brinquedos e materiais; É o último a ser escolhido para compor times em esportes ou atividades motoras) estão localizados na primeira parte do questionário referente à "Habilidade e mobilidade para participar de jogos". Na avaliação da validade das brincadeiras infantis, incluídas na primeira parte do questionário, cinco das 28 atividades ficaram abaixo do critério de $80 \%$ (Assistir televisão; Skate, patinete e patins; Parque eletrônico; Vídeo-game; Coloções, álbum de figurinhas).

Tabela 1 - Percentuais médios de escores indicativos de boa qualidade dos itens de cada parte dos Questionários

\begin{tabular}{|c|c|c|c|}
\hline Questionário de Pais & $\begin{array}{l}\text { Percentual médio de } \\
\quad \text { escores } 1 \text { e } 2\end{array}$ & Questionário de Professores & $\begin{array}{c}\text { Percentual médio } \\
\text { de escores } 1 \text { e } 2\end{array}$ \\
\hline $\begin{array}{l}\text { Parte 1: Mobilidade e habilidade } \\
\text { para participar de jogos e } \\
\text { brincadeiras }\end{array}$ & $86 \%$ & $\begin{array}{l}\text { Parte 1: Habilidade para expressar o que } \\
\text { está aprendendo }\end{array}$ & $83 \%$ \\
\hline Brincadeiras & $83 \%$ & & \\
\hline $\begin{array}{l}\text { Parte 2: Habilidade para } \\
\text { desempenhar atividades de vida } \\
\text { diária }\end{array}$ & $91 \%$ & $\begin{array}{l}\text { Parte 2: Habilidade para assumir o papel } \\
\text { de estudante }\end{array}$ & $92 \%$ \\
\hline $\begin{array}{l}\text { Parte 3: Habilidades relacionadas ao } \\
\text { papel de estudante }\end{array}$ & $92 \%$ & $\begin{array}{l}\text { Parte 3: Mobilidade e participação em } \\
\text { jogos e brincadeiras }\end{array}$ & $87 \%$ \\
\hline $\begin{array}{l}\text { Parte 4: Comportamento, hábitos e } \\
\text { rotinas }\end{array}$ & $91 \%$ & $\begin{array}{l}\text { Parte 4: Desempenho em atividades de } \\
\text { vida diária }\end{array}$ & $77 \%$ \\
\hline
\end{tabular}

Escore 1 = Concordo totalmente; Escore 2 = Concordo parcialmente.

No Questionário de Professores, avaliado por profissionais e professores, do total de 73 itens, 14 (19,2\%) obtiveram média de qualidade abaixo de $80 \%$, sendo que quatro deles se encontram na primeira parte do questionário (Maneja apontador e faz ponta corretamente no lápis; Usa computador com habilidade e velocidade apropriadas; Se expressa verbalmente, fala compreensivel; Parece saber mais do que consegue expressar), dois na terceira parte (Entra e sai do ônibus escolar ou do carro com facilidade e independência; É o último a ser escolhido para compor times em esportes ou atividades motoras) e oito na quarta parte (Guarda materiais na estante, carteira ou local designado; Usa o banheiro e faz higiene pessoal; Veste blusa ou jaqueta; Veste uniforme de ginástica; Calça meias e sapatoltênis; Amarra sapato ou tênis; Maneja/manipula fechos, botões, fivelas; Abre ou fecha portas e maneja trincos acessiveis para crianças).

Embora a avaliação global dos itens tenha sido positiva, os juízes do painel comentaram que um problema em potencial é que os questionários eram muito longos e cansativos para responder. Com base nessa informação, 
LACERDA, T. T. B. et al. Validade de conteúdo de questionários. Rev. Ter. Ocup. Univ. São Paulo, v. 18, n. 2, p. 63-77, maio/ago., 2007.

nos percentuais de qualidade, nas sugestões dos juízes e no julgamento clínico das autoras, passou-se à revisão dos questionários. Itens considerados de boa qualidade, mas com problemas na redação, foram revisados, de acordo com instruções dos juízes. Itens que não atingiram o critério de $80 \%$ de qualidade foram excluídos, a exceção de dois itens do Questionário de Pais (Assistir Televisão e Videogame) que, apesar da pobre pontuação, estão incluídos na maioria dos questionários para detecção de TDC. Outros dois itens (É o último a ser escolhido para compor times em esportes ou atividades motoras; Se expressa verbalmente, fala compreensível) também foram mantidos pelo fato de serem considerados relevantes, pelas autoras, para esse tipo de população.

As modificações que resultaram na versão final dos questionários incluíram a revisão na redação de alguns itens, a exclusão tanto de itens com avaliação baixa como com conteúdo redundante ou que os juízes tiveram dificuldade para entender, o agrupamento de itens semelhantes e o acréscimo de itens sugeridos pelo painel. $\mathrm{Na}$ Tabela 1 apresentamos um resumo das modificações feitas. A versão final do Questionário de Pais passou a contar com 101 itens e o de Professores com 63 itens. Cópia dos Questionários, ainda em fase experimental, pode ser obtida com a segunda autora.

Tabela 2 - Número de modificações feitas nos questionário após painel.

\begin{tabular}{l|l|l}
\hline $\begin{array}{l}\text { Modificações } \\
\text { realizadas após painel }\end{array}$ & $\begin{array}{l}\text { Questionário } \\
\text { de Pais }\end{array}$ & $\begin{array}{l}\text { Questionário } \\
\text { de Professores }\end{array}$ \\
\hline $\begin{array}{l}\text { 1. Revisões na redação } \\
\text { dos itens }\end{array}$ & 7 & 4 \\
\hline $\begin{array}{l}\text { 2. Exclusão de itens com } \\
\text { média }<80 \%\end{array}$ & 8 & 10 \\
\hline $\begin{array}{l}\text { 3. Agrupamento de itens } \\
\text { semelhantes }\end{array}$ & 2 & 0 \\
\hline $\begin{array}{l}\text { 4. Acréscimo de itens } \\
\text { sugeridos }\end{array}$ & 2 & 0 \\
\hline
\end{tabular}

\section{DISCUSSÃO}

Os resultados da avaliação dos itens dos questionários da ACOORDEM dão suporte à sua validade de conteúdo. Os procedimentos utilizados neste trabalho foram semelhantes aos usados por vários outros autores para estabelecer a validade de conteúdo de testes de desenvolvimento infantil (HALEY et al., 1991; HARRIS; DANIELS, 1996). Embora não haja critério estabelecido na literatura para determinar o número ideal de juízes no painel, há indicações de que 20 participantes é apropriado. Este número foi usado nos estudos de Harris e Daniel (1996) e de Palisano et al. (1997) para avaliar o conteúdo do Harris Infant Neuromotor Scale e do Sistema de Classificação da Função Motora Grossa, respectivamente. Portanto, como o presente estudo contou com 26 juízes entre terapeutas ocupacionais, pesquisadores, pais e professores, conclui-se que esse número esta de acordo com procedimentos relatados na literatura.

Os dados sobre a opinião dos participantes do painel indicam que todas as partes dos questionários são relevantes e fáceis de responder por pais e professores. Todos os profissionais demonstraram muito interesse na validação do teste e relataram que sentem necessidade de um instrumento semelhante para avaliar a criança na prática clínica e em pesquisa. Essa afirmação nos encoraja a dar continuidade ao processo de criação dos questionários, que se dará em um longo processo, até a sua validação final.

A revisão dos questionários, realizada a partir do painel, contribuiu para redução no número de itens e para confirmar tanto a validade de conteúdo do instrumento como sua adequação às necessidades de profissionais que atuam nessa área. A revisão na redação de alguns itens não implicou em mudança no sentido, apenas serviu para melhorar a compreensão do item, como por exemplo, o item "anda com boa postura e facilidade" que foi substituído por "anda com boa postura e agilidade". Por outro lado, a revisão de alguns itens resultou em pequena modificação no sentido, como o item "gosta de brincadeiras mais paradas" que mudou para "prefere brincadeiras mais paradas". As atividades de "assistir televisão" e "videogame" listadas na sessão de Brincadeiras no Questionário de Pais, apesar de terem obtido média abaixo de $80 \%$, foram mantidas por serem atividades muito comuns na infância e a literatura indica que é comum que a pobre habilidade motora leve a criança a escolher atividades mais sedentárias (CAIRNEY et al., 2005).

Os itens "Bicicleta" e "Skate, patinete e patins", também da parte de Brincadeiras, foram agrupados por concluirmos que representam o mesmo tipo de habilidade, ou atividades que envolvem equilíbrio. Estes itens, apesar de terem obtido avaliação baixa pelo painel, também foram mantidos por serem considerados importantes para discriminar crianças com pobre habilidade motora. Assim como esses, outros dois itens (ex: É o último a ser escolhido para compor times em esportes ou atividades 
motoras; Se expressa verbalmente, fala compreensivel) que também obtiveram média abaixo de $80 \%$ foram mantidos, por serem considerados relevantes, de acordo com a literatura na área e julgamento clínico das pesquisadoras. Foi realizada revisão na redação desses itens, para melhorar a clareza.

No Questionário de Pais não houve nenhum item nas partes de "habilidade para desempenhar atividades de vida diária", "habilidades relacionadas ao papel de estudante" e "comportamento, hábitos e rotinas" com avaliação abaixo da média, o que indica que pais e profissionais consideram essas habilidades relevantes para avaliar o desempenho em casa.

No Questionário de Professores, a maioria dos itens que descreviam o desempenho nas AVD, como "veste blusa ou jaqueta", "calça meias e sapatos/tênis" ou "veste uniforme de ginástica", não atingiram o percentual de qualidade de $80 \%$ e foram excluídos. Tais dados indicam que essas atividades são mais difíceis de serem observadas pelas professoras no ambiente escolar brasileiro e sua exclusão não trará problemas, uma vez que esses itens também são observados no Questionário de Pais.

Brincadeiras como "adoleta e jogos de mão", "tapão" e "três-marias" também foram excluídas apesar de terem conseguido atingir media acima de $80 \%$. Curiosamente, muitos componentes do painel não as conheciam, talvez por terem cunho regional e, desta forma, optamos por sua exclusão. Por outro lado, foi aceita sugestão de inclusão de brincadeiras representativas de crianças de baixa renda, como "soltar pipa" e "bolinha de gude".

Alguns itens foram excluídos por serem considerados de difícil observação (ex: maneja apontador e faz ponta), por estarem redundantes (ex: prefere brincar com colegas da sua idade), por não representarem à realidade da maioria das crianças (ex: usa computador com habilidade e velocidade apropriada), ou ainda porque a pontuação do painel indicou que os juízes tiveram dificuldade para entender o que o item realmente queria dizer (ex: parece saber mais do que consegue expressar). Uma limitação óbvia do estudo é o fato que a grande maioria dos participantes do painel, exceto dois, residiam na mesma localidade, o que aumentou a possibilidade de viés cultural. Além disso, os pais selecionados eram todos de nível sócio-econômico mais elevado e os professores lecionavam em escolas privadas. Os questionários foram enviados propositalmente apenas para esses pais, pois acreditamos que eles teriam maior habilidade para ler e responder bem às perguntas em questão. Já entre os professores, foram feitas tentativas de obter informações com professores de escolas públicas. Dez questionários foram enviados para três escolas públicas, mas nenhum deles foi preenchido. Isso talvez se deva à sobrecarga de tarefas a que estão sujeitos os professores de escolas públicas, associado ao desvinculamento da área de pesquisa, o que diminui o interesse em participar deste tipo de atividade.

\section{CONCLUSÃO}

O próximo passo no processo de criação do teste é a revisão dos Questionários seguida de aplicação em amostragem mais diversificada, para identificar se os itens discriminam crianças com e sem comprometimento motor. Novamente, alguns itens serão descartados e outros revisados, até que se atinja o formato final dos questionários, que vão entrar em processo de validação e derivação de normas de desempenho por idade.

Os problemas relacionados ao transtorno de coordenação motora em crianças em idade escolar ainda são pouco discutidos em nosso país, mas eles apresentam consequiências negativas a curto e longo prazo nas atividades de vida diária, acadêmicas e sociais. É imprescindível, portanto, contarmos com instrumentos práticos, confiáveis e validados culturalmente para detecção dessa condição, como é o objetivo dos Questionários de Pais e Professores da ACOORDEM. 
LACERDA, T. T. B. et al. Validade de conteúdo de questionários. Rev. Ter. Ocup. Univ. São Paulo, v. 18, n. 2, p. 63-77, maio/ago., 2007.

\section{Anexo 1 - QUESTIONÁRIO DE PAIS}

Responda as questões, considerando o critério abaixo. Procure responder a todas as perguntas.

$1=$ Sempre - comportamento sempre observado (100\%)

2 = Freqüentemente - comporta-se assim a maioria das vezes ( $80 \%)$

3 = Às vezes - comportamento começa a aparecer (50\% do tempo), desempenho inconsistente

4 = Raramente - comportamento observado ocasionalmente (20\%) ou com bastante suporte

$5=$ Nunca - não faz, não sabe, não tem interesse (0\%)

N = Não se aplica - não observado ou não aplicável à situação

\section{Mobilidade e habilidade para participar de jogos e brincadeiras}

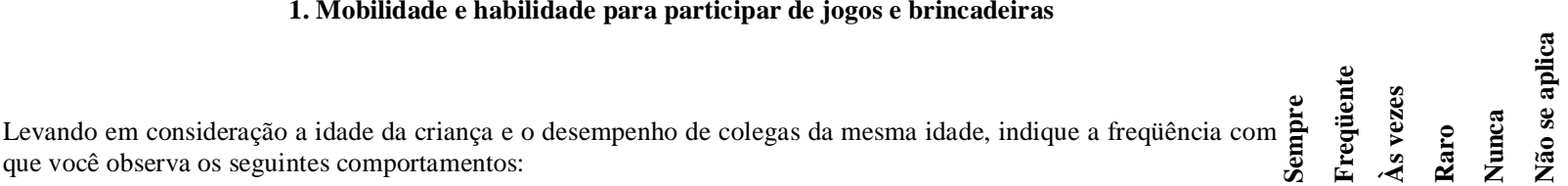

\begin{tabular}{|c|c|}
\hline 1. & Mantém boa postura sentado(a) \\
\hline 2. & Anda com boa postura e desenvoltura \\
\hline 3. & Gosta de caminhadas, não se cansa facilmente \\
\hline 4. & Corre com agilidade, não se cansa facilmente \\
\hline 5. & Sobe e desce escadas com desenvoltura \\
\hline 6. & Salta ou pula obstáculos com agilidade \\
\hline 7. & Entra e sai do ônibus ou do carro com facilidade \\
\hline 8. & Joga futebol com agilidade \\
\hline 9. & Agarra bola com facilidade \\
\hline 10. & Acerta bola em alvo ou joga para outra pessoa com facilidade \\
\hline 11. & Anda de bicicleta com segurança e agilidade \\
\hline 12. & Anda de patinete, skate, patins e similares com segurança e agilidade \\
\hline 13. & Pula corda com agilidade \\
\hline 14. & Usa brinquedos móveis, como balanços e gangorra, com facilidade \\
\hline 15. & É bom de bola, os colegas chamam para brincar ou participar de atividades físicas \\
\hline 16. & Gosta de participar de atividades físicas ou esportivas \\
\hline 17. & É habilidoso(a) e gosta de fazer atividades manuais \\
\hline 18. & Maneja controle de videogame com destreza \\
\hline 19. & Aprende tarefas motoras novas com facilidade e rapidez (ex: andar de bicicleta, nadar) \\
\hline 20. & Brinca de maneira organizada \\
\hline 21. & É cuidadoso com os brinquedos e materiais \\
\hline 22. & Gosta de brincadeiras mais paradas (ex: ler, contar histórias) \\
\hline 23. & Prefere brincar sentado ou mesmo deitado \\
\hline 24. & Ao invés de participar, prefere observar outras crianças brincando \\
\hline 25. & Ao escrever ou desenhar debruça sobre a mesa, rosto próximo ao papel \\
\hline 26. & Tropeça, cai, propenso a acidentes \\
\hline 27. & Tromba, quebra brinquedos, objetos escapam das mãos \\
\hline 28. & É o último a ser escolhido para compor times em esportes ou atividades motoras \\
\hline 29. & Inquieto, movimenta ou mexe muito o corpo (ex: balança, cruza e descruza as pernas) \\
\hline 30. & Agitado, muda de atividade a cada 5-10 minutos \\
\hline 31. & Frustra-se facilmente e abandona atividades motoras mais difíceis \\
\hline 32. & Prefere brincar com crianças bem mais jovens \\
\hline 33. & Prefere brincar sozinho \\
\hline 34. & Prefere brincar com adultos ou crianças bem mais velhas \\
\hline 35. & Prefere brincar com colegas da sua idade \\
\hline
\end{tabular}

Assinale no quadro a seguir as atividades preferidas da criança, a freqüência e com quem ela geralmente faz a atividade: 
LACERDA, T. T. B. et al. Validade de conteúdo de questionários. Rev. Ter. Ocup. Univ. São Paulo, v. 18, n. 2, p. 63-77, maio/ago., 2007.

\begin{tabular}{|c|c|c|c|c|c|c|c|c|c|c|c|}
\hline \multirow[t]{2}{*}{ ATIVIDADES } & \multicolumn{4}{|c|}{ GOSTA } & \multicolumn{4}{|c|}{ FREQÜÊENCIA } & \multicolumn{3}{|c|}{ COM QUEM BRINCA } \\
\hline & $\stackrel{?}{\stackrel{0}{\Xi}}$ & 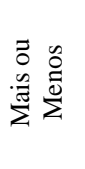 & $\begin{array}{l}\stackrel{0}{0} \\
\varrho\end{array}$ & $\begin{array}{l}\frac{\pi}{0} \\
0 \\
0 \\
0 \\
\text { : } \\
\text { Z }\end{array}$ & 悹 & $\sum_{i}^{\infty}$ & 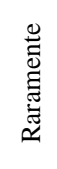 & 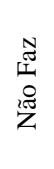 & $\begin{array}{l}\text { : } \\
\text { : } \\
\text { \& }\end{array}$ & 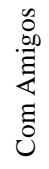 & 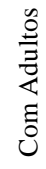 \\
\hline $\begin{array}{l}\text { Pegador / Esconde- } \\
\text { esconde }\end{array}$ & & & & & & & & & & & \\
\hline Amarelinha & & & & & & & & & & & \\
\hline Futebol & & & & & & & & & & & \\
\hline Vôlei ou basquete & & & & & & & & & & & \\
\hline $\begin{array}{l}\text { Peteca, tênis, jogos com } \\
\text { raquete }\end{array}$ & & & & & & & & & & & \\
\hline $\begin{array}{l}\text { Outras brincadeiras com } \\
\text { bola }\end{array}$ & & & & & & & & & & & \\
\hline Nadar & & & & & & & & & & & \\
\hline Pula-corda, elástico & & & & & & & & & & & \\
\hline Assistir televisão & & & & & & & & & & & \\
\hline Bicicleta & & & & & & & & & & & \\
\hline Skate, patinete e patins & & & & & & & & & & & \\
\hline $\begin{array}{l}\text { Parque (escorregador, } \\
\text { balanço) }\end{array}$ & & & & & & & & & & & \\
\hline $\begin{array}{l}\text { Parque eletrônico (roda } \\
\text { gigante, montanha russa) }\end{array}$ & & & & & & & & & & & \\
\hline Boneca / bonecos de ação & & & & & & & & & & & \\
\hline $\begin{array}{l}\text { Casinha, comidinha, } \\
\text { mamãe e filhinha, } \\
\text { escolinha }\end{array}$ & & & & & & & & & & & \\
\hline Cantar e representar & & & & & & & & & & & \\
\hline Dançar, aulas de dança & & & & & & & & & & & \\
\hline $\begin{array}{l}\text { Tocar instrumento } \\
\text { musical }\end{array}$ & & & & & & & & & & & \\
\hline $\begin{array}{l}\text { Jogos de construção / } \\
\text { Lego }\end{array}$ & & & & & & & & & & & \\
\hline Quebra-cabeça & & & & & & & & & & & \\
\hline Videogame & & & & & & & & & & & \\
\hline $\begin{array}{l}\text { Coleções, álbum de } \\
\text { figurinhas }\end{array}$ & & & & & & & & & & & \\
\hline Ler livros e revistinhas & & & & & & & & & & & \\
\hline Tapão & & & & & & & & & & & \\
\hline Três Marias & & & & & & & & & & & \\
\hline Desenhar, pintar e colorir & & & & & & & & & & & \\
\hline Jogos de mesa / Baralho & & & & & & & & & & & \\
\hline Adoleta e jogos de mão & & & & & & & & & & & \\
\hline
\end{tabular}

Sempre $=$ desempenho diário ou, se tem oportunidade, freqüente durante a semana

Às vezes $=$ desempenho ocasional, cerca de uma vez por semana, quinzenal

Raramente $=$ muito pouco freqüente, $1 \mathrm{vez}$ por mês ou menos

Qual a brincadeira ou brinquedo preferido da criança?

Caso não apareçam na lista acima, indique outras brincadeiras que sua criança gosta de fazer: 
LACERDA, T. T. B. et al. Validade de conteúdo de questionários. Rev. Ter. Ocup. Univ. São Paulo, v. 18, n. 2, p. 63-77, maio/ago., 2007.

\section{Habilidade para desempenhar atividades de vida diária}

Indique a freqüência com que sua criança desempenha com independência e uso eficiente do tempo as seguintes atividades:

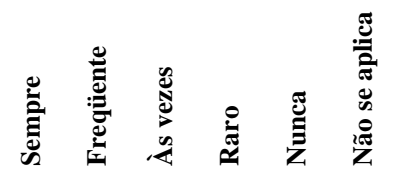

\begin{tabular}{l}
\hline (a) Abre e coloca pasta dental na escova \\
\hline (b) Escova os dentes \\
\hline (c) Lava e seca as mãos e o rosto \\
\hline (d) Se limpa, após o uso do banheiro \\
\hline (e) Toma banho \\
\hline (f) Penteia e/ou escova os cabelos \\
\hline (g) Tira todas as peças de roupa (ex: para tomar banho) \\
\hline (h) Veste todas as peças de roupa (ex; uniforme escolar) \\
\hline (i) Maneja fechos e botões \\
\hline (j) Calça sapatos de diferentes modelos (ex: tênis, sandália, mocassim) \\
\hline (k) Amarra sapatos, dando laço \\
\hline (l) Alimenta-se sozinho com garfo \\
\hline (m) Alimenta-se sozinho com colher \\
\hline (n) Usa faca para cortar alimentos \\
\hline (o) Escolhe a comida e serve o prato \\
\hline (p) Serve água de jarro ou garrafa \\
\hline (q) Escolhe e tira roupas no armário \\
\hline (r) Guarda roupas no armário ou gavetas \\
\hline (s) Organiza e guarda pertences e/ou brinquedos \\
\hline
\end{tabular}

Pense sobre as rotinas diárias com sua criança (levantar, vestir, comer, tomar banho, fazer dever de casa, brincar, ir para cama). Tem algum desses momentos que você considera difícil ou desgastante na relação diária com sua criança?

( ) $\operatorname{Sim}($ ) Não

Se sim, qual deles?

Observações e comentários: 
LACERDA, T. T. B. et al. Validade de conteúdo de questionários. Rev. Ter. Ocup. Univ. São Paulo, v. 18, n. 2, p. 63-77, maio/ago., 2007.

\section{Habilidades relacionadas ao papel de estudante}

Levando em consideração a idade da criança e o desempenho de colegas da mesma idade, indique a freqüência com que você observa os comportamentos listados abaixo:

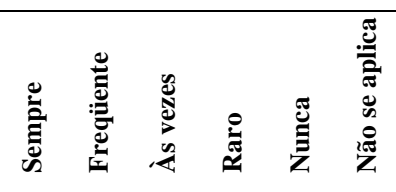

\begin{tabular}{|c|c|c|c|c|c|c|}
\hline 1. Escreve com facilidade, sem esforço evidente & 1 & 2 & 3 & 4 & 5 & $\mathrm{~N}$ \\
\hline 2. Deixa espaços apropriados entre letras e palavras & 1 & 2 & 3 & 4 & 5 & $\mathrm{~N}$ \\
\hline 3. Escrita legível, produz letras e palavras legíveis & 1 & 2 & 3 & 4 & 5 & $\mathrm{~N}$ \\
\hline 4. Escrita legível, produz números legíveis & 1 & 2 & 3 & 4 & 5 & $\mathrm{~N}$ \\
\hline 5. Copia material escrito correta e legivelmente & 1 & 2 & 3 & 4 & 5 & $\mathrm{~N}$ \\
\hline 6. $\quad$ Escreve com velocidade apropriada & 1 & 2 & 3 & 4 & 5 & $\mathrm{~N}$ \\
\hline 7. Colore e desenha com facilidade & 1 & 2 & 3 & 4 & 5 & $\mathrm{~N}$ \\
\hline 8. Recorta papel com tesoura com facilidade & 1 & 2 & 3 & 4 & 5 & $\mathrm{~N}$ \\
\hline 9. Escreve com pressão adequada do lápis (nem forte nem leve demais) & 1 & 2 & 3 & 4 & 5 & $\mathrm{~N}$ \\
\hline 10. Faz o para-casa no tempo previsto, sem maiores dificuldades & 1 & 2 & 3 & 4 & 5 & $\mathrm{~N}$ \\
\hline 11. Observa-se tensão ou maior esforço durante a escrita & 1 & 2 & 3 & 4 & 5 & $\mathrm{~N}$ \\
\hline $\begin{array}{l}\text { 12. Caderno/trabalhos sujos, manchados de tinta ou de borracha, amassados ou rasgados, devido a } \\
\text { dificuldades motoras }\end{array}$ & 1 & 2 & 3 & 4 & 5 & $\mathrm{~N}$ \\
\hline 13. Recusa-se a fazer trabalhos que envolvem escrever, desenhar e colorir & 1 & 2 & 3 & 4 & 5 & $\mathrm{~N}$ \\
\hline $\begin{array}{l}\text { 14. Mostra sinais de cansaço em trabalhos de escrita (ex: balança as mãos, paradas para descanso, } \\
\text { lentidão) }\end{array}$ & 1 & 2 & 3 & 4 & 5 & $\mathrm{~N}$ \\
\hline 15. Troca de mãos quando usa o lápis, colher ou outros utensílios & 1 & 2 & 3 & 4 & 5 & $\mathrm{~N}$ \\
\hline
\end{tabular}

\section{Comportamento, hábitos e rotinas}

Levando em consideração a idade da criança e o desempenho de colegas da mesma idade, indique a frequiência com que você observa os seguintes comportamentos:

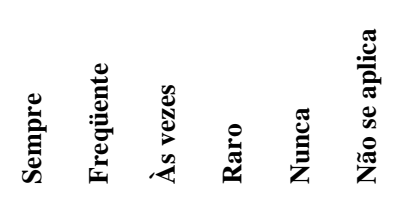

\begin{tabular}{|c|c|c|c|c|c|c|}
\hline 1. É organizado(a) e segue as rotinas da casa & 1 & 2 & 3 & 4 & 5 & $\mathrm{~N}$ \\
\hline 2. Obedece horários específicos para estudo, brincadeira, TV, banho, dormir & 1 & 2 & 3 & 4 & 5 & $\mathrm{~N}$ \\
\hline 3. Apresenta bom comportamento em restaurantes e locais públicos e festas & 1 & 2 & 3 & 4 & 5 & $\mathrm{~N}$ \\
\hline $\begin{array}{l}\text { 4. Acompanha os pais ao shopping center ou supermercado, ajuda nas compras e espera, quando } \\
\text { necessário }\end{array}$ & 1 & 2 & 3 & 4 & 5 & $\mathrm{~N}$ \\
\hline 5. Tem bom comportamento quando visita colegas, sem supervisão dos pais & 1 & 2 & 3 & 4 & 5 & $\mathrm{~N}$ \\
\hline $\begin{array}{l}\text { 6. Apresenta bom comportamento em locais onde precisa ficar quieto por mais tempo (ex: igreja, } \\
\text { teatro) }\end{array}$ & 1 & 2 & 3 & 4 & 5 & $\mathrm{~N}$ \\
\hline $\begin{array}{l}\text { 7. É prazeroso ir com a criança à praia, ao clube ou ao parque, pois ele(a) se diverte e se comporta } \\
\text { apropriadamente }\end{array}$ & 1 & 2 & 3 & 4 & 5 & $\mathrm{~N}$ \\
\hline $\begin{array}{l}\text { 8. Fica extremamente agitado(a) em festas, acabando por brigar, chorar ou precisar ir embora mais } \\
\text { cedo, devido ao comportamento }\end{array}$ & 1 & 2 & 3 & 4 & 5 & $\mathrm{~N}$ \\
\hline $\begin{array}{l}\text { 9. Tem dificuldade para aceitar mudanças na rotina, faz birra ou fica irritado(a) quando acontece } \\
\text { alguma coisa diferente ou inesperada }\end{array}$ & 1 & 2 & 3 & 4 & 5 & $\mathrm{~N}$ \\
\hline $\begin{array}{l}\text { 10. É difícil andar com a criança na rua, pois ele(a) pode correr e atravessar a rua, sem atentar para o } \\
\text { perigo }\end{array}$ & 1 & 2 & 3 & 4 & 5 & $\mathrm{~N}$ \\
\hline 11. A família restringe suas atividades sociais devido ao comportamento da criança & 1 & 2 & 3 & 4 & 5 & $\mathrm{~N}$ \\
\hline
\end{tabular}

Sua opinião é importante:

Qual a sua opinião geral sobre o questionário? ( ) Ótimo $\quad$ ( ) Bom ( ) Regular （ ) Fraco

$\begin{array}{llll}\text { Você acredita que os pais terão facilidade e interesse em respondê-lo? } & \text { ( ) } \operatorname{sim} & \text { ( ) não }\end{array}$ 
LACERDA, T. T. B. et al. Validade de conteúdo de questionários. Rev. Ter. Ocup. Univ. São Paulo, v. 18, n. 2, p. 63-77, maio/ago., 2007.

Anexo 2 - Questionário de professores

Responda as questões, considerando o critério abaixo. Procure responder a todas as perguntas.

$1=$ Sempre - comportamento sempre observado (100\%)

2 = Freqüentemente - comporta-se assim a maioria das vezes ( $80 \%)$

3 = Às vezes - comportamento começa a aparecer (50\% do tempo), desempenho inconsistente

4 = Raramente - comportamento observado ocasionalmente (20\%) ou com bastante suporte

$5=$ Nunca - não faz, não sabe, não tem interesse $(0 \%)$

$\mathrm{N}$ = Não aplica - não observado ou não aplicável à situação

\section{Habilidade motora para expressar o que esta aprendendo}

Levando em consideração a idade da criança e o desempenho de colegas da mesma idade, indique a freqüência com que você observa os seguintes comportamentos:

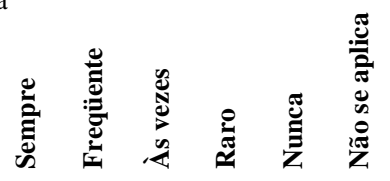

1. Escreve com facilidade, sem esforço evidente

2. Deixa espaços apropriados entre letras e palavras

3. Escreve letras e números de tamanho apropriado

4. Escreve sobre a linha ou no espaço designado para a escrita

5. Inicia e termina a escrita no local apropriado

6. Escrita legível - produz letras e números com qualidade apropriada

7. Copia material escrito correta e legivelmente

8. Escreve com velocidade apropriada

9. Colore e desenha com facilidade

10. Recorta com tesoura com facilidade

11. Maneja apontador e faz ponta corretamente no lápis

12. Usa computador com habilidade e velocidade apropriadas

13. Escreve com pressão adequada no lápis (nem forte nem leve demais)

14. Se expressa verbalmente, fala compreensível

15. Caderno/trabalhos sujos, manchados de tinta ou de borracha, amassados ou rasgados, devido a dificuldades motoras

16. Recusa-se a fazer trabalhos que envolvem escrever, desenhar e colorir

17. Mostra sinais de cansaço em trabalhos de escrita (ex: balança as mãos, paradas para descanso, lentidão)

18. Troca de mãos quando usa o lápis

19. Parece saber mais do que consegue expressar (escrito e verbal) 
LACERDA, T. T. B. et al. Validade de conteúdo de questionários. Rev. Ter. Ocup. Univ. São Paulo, v. 18, n. 2, p. 63-77, maio/ago., 2007.

\section{Habilidade para assumir o papel de estudante}

Levando em consideração a idade da criança e o desempenho de colegas da mesma idade, indique a frequiência com que você observa os seguintes comportamentos:

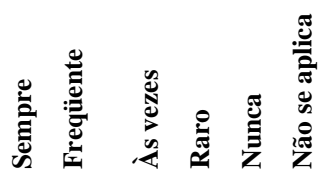

\begin{tabular}{|c|c|c|c|c|c|c|}
\hline 1. Entende as regras da sala de aula & 1 & 2 & 3 & 4 & 5 & $\mathrm{~N}$ \\
\hline 2. Tem amigos, se dá bem com os colegas & 1 & 2 & 3 & 4 & 5 & $\mathrm{~N}$ \\
\hline 3. Trabalha de maneira independente para concluir os trabalhos solicitados & 1 & 2 & 3 & 4 & 5 & $\mathrm{~N}$ \\
\hline 4. Segue instruções verbais ou solicitações da professora & 1 & 2 & 3 & 4 & 5 & $\mathrm{~N}$ \\
\hline 6. É cooperativo(a) e colabora com os colegas em trabalhos grupais & 1 & 2 & 3 & 4 & 5 & $\mathrm{~N}$ \\
\hline 7. Solicita ajuda quando necessário & 1 & 2 & 3 & 4 & 5 & $\mathrm{~N}$ \\
\hline 8. Mantém atenção durante as tarefas & 1 & 2 & 3 & 4 & 5 & $\mathrm{~N}$ \\
\hline 10. Mantém seus pertences organizados e prontos para uso no espaço designado & 1 & 2 & 3 & 4 & 5 & $\mathrm{~N}$ \\
\hline 11. Não interrompe os outros, aguarda sua vez para falar, de acordo com as regras da sala (ex: levantar a mão) & 1 & 2 & 3 & 4 & 5 & $\mathrm{~N}$ \\
\hline 12. Apresenta comportamento adequado em passeios, excursões ou outras atividades extraclasse & 1 & 2 & 3 & 4 & 5 & $\mathrm{~N}$ \\
\hline 13. Fica muito excitado(a) e tem dificuldade para se acalmar & 1 & 2 & 3 & 4 & 5 & $\mathrm{~N}$ \\
\hline 14. Chora facilmente & 1 & 2 & 3 & 4 & 5 & $\mathrm{~N}$ \\
\hline 15. Tem dificuldade para passar de atividades mais agitadas para atividades mais calmas & 1 & 2 & 3 & 4 & 5 & $\mathrm{~N}$ \\
\hline 16. Muda tanto de atividade, que acaba não conseguindo concluir as tarefas & 1 & 2 & 3 & 4 & 5 & $\mathrm{~N}$ \\
\hline 18. Solicita muita ajuda, mesmo quando desnecessária & 1 & 2 & 3 & 4 & 5 & $\mathrm{~N}$ \\
\hline 19. Trabalha ou brinca sozinho, tem dificuldade para fazer amigos & 1 & 2 & 3 & 4 & 5 & $\mathrm{~N}$ \\
\hline 20. Tem comportamento de oponência/resistência, não aceita regras & 1 & 2 & 3 & 4 & 5 & $\mathrm{~N}$ \\
\hline 21. Muito tímido(a), não conversa com os amigos ou com a professora & 1 & 2 & 3 & 4 & 5 & $\mathrm{~N}$ \\
\hline
\end{tabular}

\section{Mobilidade e participação em jogos e brincadeiras}

Levando em consideração a idade da criança e o desempenho de colegas da mesma idade, indique a freqüência com que ocê observa os seguintes comportamentos:

\begin{tabular}{|c|c|}
\hline 1. & Mantém boa postura quando sentado(a) na carteira ou no chão \\
\hline 2. & Anda e corre com boa postura e desenvoltura \\
\hline 3. & Pula ou salta obstáculos com habilidade \\
\hline 4. & Acompanha a turma na fila, indo de um lugar a outro na escola \\
\hline 5. & Acompanha o ritmo da turma em passeios ou caminhadas \\
\hline 6. & Carrega a mochila, livros e materiais sem dificuldade ou cansaço excessivo \\
\hline 7. & Transporta materiais, livros e cadernos pela sala, sem trombar nas carteiras \\
\hline 8. & Participa com desenvoltura das aulas de educação física \\
\hline 9. & Gosta de participar de atividades físicas e esportivas \\
\hline 10. & É habilidoso(a) e gosta de aula de artes ou de trabalhos manuais \\
\hline 11. & Usa brinquedos móveis, como balanços e gangorra, com facilidade \\
\hline 12. & Participa de brincadeiras com bola e atividades motoras durante o recreio \\
\hline 13. & Sobe e desce escadas com agilidade \\
\hline 14. & Entra e sai do ônibus escolar ou do carro com facilidade e independência \\
\hline 15. & $\begin{array}{l}\text { Anda pela escola sem se perder, reconhece a localização da sala de aula, do banheiro e outros pontos } \\
\text { importantes para mobilidade na escola }\end{array}$ \\
\hline 16. & Fica muito inclinado deitado sobre a carteira ou com a cabeça apoiada na mão \\
\hline & Inquieto, se move muito na carteira, sempre mexendo com alguma coisa \\
\hline & É o último a ser escolhido para compor times em esportes ou atividades motoras \\
\hline & Ao invés de participar, prefere observar outras crianças brincando \\
\hline & Tropeça, cai facilmente, propenso a acidentes \\
\hline 21. & Usa o corrimão ou a ajuda dos colegas para subir ou descer escadas \\
\hline
\end{tabular}


LACERDA, T. T. B. et al. Validade de conteúdo de questionários. Rev. Ter. Ocup. Univ. São Paulo, v. 18, n. 2, p. 63-77, maio/ago., 2007.

\section{Desempenho de atividades de vida diária}

Indique a freqüência com que a criança desempenha com independência e uso eficiente do tempo as seguintes atividades:

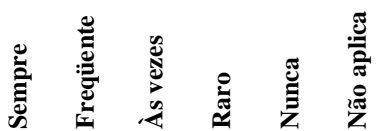

\begin{tabular}{|c|c|c|c|c|c|c|}
\hline 1. Maneja a pasta/mochila, retirando e colocando livros e materiais & 1 & 2 & 3 & 4 & 5 & $\mathrm{~N}$ \\
\hline 2. Guarda materiais na estante, carteira ou local designado & 1 & 2 & 3 & 4 & 5 & $\mathrm{~N}$ \\
\hline 3. Come merenda, maneja merendeira, embalagens e alimentos & 1 & 2 & 3 & 4 & 5 & $\mathrm{~N}$ \\
\hline 4. Lava e enxuga mãos e rosto & 1 & 2 & 3 & 4 & 5 & $\mathrm{~N}$ \\
\hline 5. Retira e coloca peças de roupa para uso do banheiro & 1 & 2 & 3 & 4 & 5 & $\mathrm{~N}$ \\
\hline 6. Usa o banheiro e faz higiene pessoal & 1 & 2 & 3 & 4 & 5 & $\mathrm{~N}$ \\
\hline 7. Veste blusa ou jaqueta & 1 & 2 & 3 & 4 & 5 & $\mathrm{~N}$ \\
\hline 8. Veste uniforme de ginástica & 1 & 2 & 3 & 4 & 5 & $\mathrm{~N}$ \\
\hline 9. Calça meias e sapato/tênis & 1 & 2 & 3 & 4 & 5 & $\mathrm{~N}$ \\
\hline 10. Amarra sapato ou tênis (dá laço) & 1 & 2 & 3 & 4 & 5 & $\mathrm{~N}$ \\
\hline 11. Maneja/manipula fechos, botões, fivelas & 1 & 2 & 3 & 4 & 5 & $\mathrm{~N}$ \\
\hline $\begin{array}{l}\text { 12. Abre ou fecha portas e maneja trincos acessíveis para crianças (ex: porta do } \\
\text { banheiro) }\end{array}$ & 1 & 2 & 3 & 4 & 5 & $\mathrm{~N}$ \\
\hline
\end{tabular}

Sua opinião é importante:

Qual a sua opinião geral sobre o questionário? ( ) Ótimo ( ) Bom ( ) Regular ( ) Fraco

Você acredita que os professores terão facilidade e interesse em respondê-lo? ( ) sim ( ) não

Agradecimentos: Agradecemos ao Conselho Nacional de Desenvolvimento Científico e Tecnológico - CNPq (Bolsa PQ no.352564/1996-2 e auxílio pesquisa no. 478469/2004-7) pelo suporte dado ao estudo.

LACERDA, T. T. B.; MAGALHÃES, L. C.; REZENDE, M. B. Content validity of motor coordination questionnaires for parents and teachers. Rev. Ter. Ocup. Univ. São Paulo, v. 18, n. 2, p. 63-77, maio/ ago., 2007.

ABSTRACT: INTRODUCTION: The term Developmental Disorder Coordination (DCD) has been used to refer to children that, in the absence of neuromotor disorders, present problems to perform daily living activities that require motor coordination. Facing the lack of appropriate motor coordination tests, standardized for the Brazilian children, the process of creation and validation of the Assessment of Motor Coordination and Dexterity (ACOORDEM) was initiated. The instrument is divided in three parts, two parts are based on direct observation of the child's motor performance and the last part consists in two structured Questionnaires, that evaluate functional skills at home and school. OBJECTIVE: The objective of this study was examine the content validity of the Parents' and Teachers' Questionnaires of the ACOORDEM. METHODS: An expert panel, composed by nine teachers, 11 parents and seven therapists, evaluated the quality of the items in the Questionnaires. The Teachers' Questionnaire is composed by 73 items and the Parents' one has 108 items. RESULTS: The results gave support to the content validity of the Parents' and Teachers' Questionnaires, since more than $87 \%$ of the items were considered as presenting good quality. CONCLUSION: As a result of the expert panel the questionnaires were revised, which contributed to item reduction and to confirm the adequacy of the items to the needs of parents and professionals that deal with children with motor coordination problems.

KEY WORDS: Child development. Motor skills. Validity of tests. Motor skills disorders. 


\section{REFERÊNCIAS}

ANASTASI, A.; URBINA S. Validade: conceitos básicos. In: Testagem psicológica. Porto Alegre: Artmed Editora, 2000. p.107127.

BATTAGLIA, M.; RUSSO, E.; BOLLA, A.; CHIUSSO, A; BERTELLI, S.; PELLEGRI, A.; BORRI, E.; MARTINUZZI, A. International classification of functioning, disability and health in a cohort of children with cognitive, motor and complex disabilities. Dev. Med. Child Neurol., v. 46, p. 98-106, 2004.

BRUININKS, R. H. Bruininks-Oseretsky test of motor proficiency. Circle Pine: American Guidance Service, 1978.

BUNDY, A.; CARTER, R. Making a difference: OTs and PTs in Public Schools. A model curriculum for preparing OT and PT students. Chicago: University of Illinois at Chicago, 1991.

CAIRNEY, J.; HAY, J. A.; FAUGHT, B. E.; WADE, T.J.; CORNA, L.; FLOURIS, A. Developmental coordination disorder, generalized self-efficacy toward physical activity, and participation in organized and free play activities. J. Pediatr., v.147, n. 4, p. 515-520, 2005.

CERMAK, S. A.; GUBBAY, S. S.; LARKIN, D. What is developmental coordination disorder? In: CERMAK, S. A.; LARKIN, D. Developmental coordination disorder. Albany, NY: Delmar, 2002.

DUNFORD, C.; STREET, E.; O’CONNELL, H.; KELLY, J.; SIBERT, J. R. Are referrals to occupational therapy for developmental coordination disorder appropriate? Arch. Dis. Child., v. 89, p. 143-147, 2004.

EXNER, C. E. Content validity of the in-hand manipulation test. Am. J. Occup. Ther., v. 47/6, p. 505-513, 1993.

GEUZE, R. H. Static balance and development coordination disorder. Hum. Mov. Sci., v. 22, p. 527-548, 2003.

GEUZE, R. H.; JONGMANS, M. J.; SCHOEMAKER, M. M.; ENGELSMAN, B. C. M. S. Clinical and research diagnostic criteria for developmental coordination disorder: a review and discussion. Hum. Mov. Sci., v. 20, p. 7-47, 2001.

GUBBAY, S. S. The clumsy child - A study of developmental apraxia and agnosic ataxia. Philadelphia: WB Sounder, 1975.

HALEY, S. M.; COSTER, W. J.; FAAS, R. M. A content validity study of pediatric evaluation of disability inventory. Pediatr. Phys. Ther., p. 177-184, 1991.

HARRIS, S. R.; DANIELS, L. E. Content validity of the Harris infant neuromotor test. Phys. Ther., v. 76, n. 6, p. 727-737, 1996.

HENDERSON, S. E.; SUDGEN, D. A. Movement assessment batery for children. Sidcup: The Psychological Corporation, 1992.

MAGALHÃES, L. C.; NASCIMENTO, V. C. S.; REZENDE, M. B. Avaliação da coordenação e destreza motora - ACOORDEM: etapas de criação e perspectivas de validação. Rev. Ter. Ocup. Univ. São Paulo, v. 14, n. 1, p. 104-12, 2004.

MANDICH, A.; POLATAJKO, H. Developmental disorder coordination: mechanisms, measurement and management. Hum. Mov. Sci., v. 22, p. 407-411, 2003.

MUTTI, M.; STERLING, H. M.; SPALDING, N. V. Quick neurological screening test. Novato:Academic Therapy Publications, 1978.

ORGANIZAÇÃO MUNDIAL DE SAÚDE, CIF: classificação internacional de funcionalidade, incapacidade e saúde. São Paulo: Editora da Universidade de São Paulo: EDUSP, 2003.

PALISANO, R.; ROSEBAUM, P.; WALTER, S.; RUSSELL, D.; ELLEN, W.; GALLUPPI, B. Development and reliability of a system to classify gross motor function in children with cerebral palsy. Dev. Med. Child Neurol., v. 39, p. 214-223, 1997.

WILSON, B. N.; KAPLAN, B. J.; CRAWFORD, S. G.; CAMPBELL, A.; DEWEY, D. Reliability and validity of a parent questionnaire on childhood motor skills. Am. J. Occup. Ther., v. 54, n. 5, p. 484-493, 2000.

Recebido para publicação: Abr./2007

Aceito para publicação: Abr./2007 